\title{
BSPD presents awards online
}

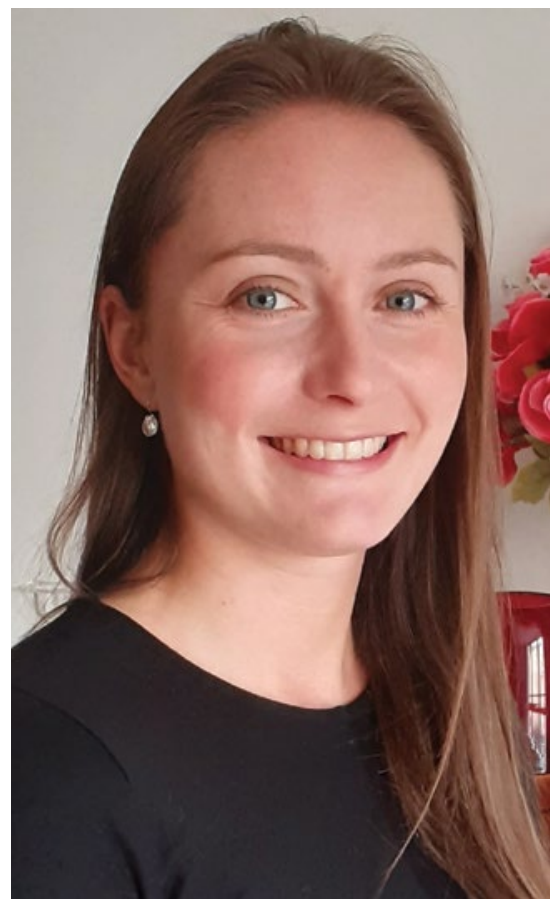

Jessica Large, winner of the BSPD's Clinical Governance Prize 2020

Although this year's British Society of Paediatric Dentistry (BSPD) Annual Conference was postponed due to the COVID-19 pandemic, the BSPD Awards went ahead, and were judged virtually for the first time.

The winning Clinical Governance Prize was a service development project introducing body mass index (BMI) screening of children attending new patient appointments at the Edinburgh Dental Institute. Submitted by Jessica Large (pictured), and entitled Let's 'Get Going': Healthy weight and healthy mouths, Jessica's project identified that $14 \%$ of children who had their BMI calculated were above a healthy weight and $4 \%$ below a healthy weight.

Children identified as above a healthy weight were offered onward referral to 'Get Going' - a local weight management service. Children below a healthy weight were offered support through their general medical practitioner.

Dr Chris Vernazza, BSPD's honorary editor and chair of BSPD's Conference Abstracts and Prizes Committee, said: 'This is the kind of important thing that we can all be doing. It's exciting to see the impact an audit can have on best practice. BSPD's Quality Improvement Research Committee will consider this as a topic for a national audit'.

Dr Vernazza was equally enthusiastic about the undergraduate poster prize, sponsored by the BSPD Teachers Branch, won by Louise Davies, of the University of Birmingham. Her title was Investigation into the Awareness of Non-Verbal Communication Tools in Dentistry.

Dr Vernazza said: 'Effective communication with our young patients and their parents is an important part of paediatric dentistry and something we want our students to excel at. It's great to see an undergraduate leading on this'.

The annual BSPD research prize is sponsored by GSK plc and in 2020 went to Risha Sanghvi, of King's College London. Her title was Evaluating the cost effectiveness of retaining compromised first permanent molars in children.

The final award of the evening was the Clinical case prize sponsored by RA Medical whose owner, Janet Pickles, was online to congratulate Maryam Ezzeldin of University Dental Hospital, Cardiff for her paper, called $A$ rare case of Stoneman Syndrome.

The quality of the entries to the BSPD Awards this year was very high and the organisers felt that having judging and presenting online worked extremely well.

\section{BSDHT and BADT launch consultation to change legislation}

The British Society of Dental Hygiene and Therapy (BSDHT) and the British Association of Dental Therapists (BADT) have been working on the NHS England project to change legislation and in collaboration with the Scottish, Welsh and Northern Ireland governments, are now consulting the public on proposed changes to the Human Medicines Regulations 2012 to include the use by dental hygienists and therapists of a mechanism called exemptions.

Dental hygienists and dental therapists are trained, indemnified and competent in the use of certain prescription only medicines. The mechanisms by which they use these medicines are varied and currently they can administer, sell and supply only by a patient specific direction (PSD) or a patient group directive (PGD).
These mechanisms have advantages and disadvantages and the profession have decided to unite to find a more effective solution to providing these medicines in a timely and cost-efficient manner.

Being able to use the exemptions mechanism will mean that:

- Dental hygienists and dental therapists will be able to supply and administer certain medicines to patients that would normally need a prescription from a dentist

- Dentists would be relieved of an administration burden

- Fewer patients would be turned away for treatment due to changes in their needs

- The dental hygienist or dental therapist would be able to treat their patient with the medicines they are trained, indemnified and competent to use in a timely fashion, resulting in fewer appointments with fewer costs incurred by patients and dental practices

- There is a reduction in the number of interruptions to a dentist to ask them to prescribe a medicine.

This would help dentists, dental hygienists and dental therapists to provide safer, quicker and more comfortable care for their patients.

The Public Consultation can be found at https://www.england.nhs.uk/medicines-2/ chief-professions-officers-medicinesmechanisms-programme/ and will run from 15 October to 10 December 2020.

Links to engagement events, further details and consultation documents can be found at the same site. 